\title{
SISFISIO: A SOFTWARE FOR TEACHING AND LEARNING PHYSIOLOGY
}

Silva, T.V. ${ }^{1}$, Alves, R.S.P. ${ }^{1}$, Avelar, J.L.V. ${ }^{2}$, Guiné, A.A.A. ${ }^{1}$, Pêgo, P.N. ${ }^{1}$, Carvalho C.V.A. ${ }^{2}$, De Mesquita J.F. ${ }^{1,3}$

Universidade Severino Sombra - Curso de ${ }^{1}$ Biomedicina $e^{2}$ de Sistemas de Informação, Vassouras; ${ }^{3}$ UNIRIO/ UNIGEN, Rio de Janeiro, RJ, Brazil.

e-mail: jfreire@biomol.net

The benefits of using interactive computer softwares in Education have been discussed for some time. This approach can improve cognitive capacity, better learning and, mainly, it makes information acquisition easier. This work presents the development of a software called SISFISIO. It is an "exercise and practice" system designed for teaching Physiology in biomedical courses. It was developed using the Delphi interface system and Macromedia Flash. The Flash components were integrated with Delphi using an ActiveX control. The internal structure of the software has two linearly-linked lists (a linked list is one of the fundamental data structures used in computer programming): one for the exercises and another for the question of each exercise. The information is stored in a text file that should be filled by the instructor. The SISFISIO software uploads this file and it fills the data structures cited above. Upon completion of a Physiology module, the student's answers can be immediately verified, the scores tallied and the duration of the exercise measured. SISFISIO was incorporated into biomedicine classes at USS. The student's evaluation, based on the 5-point Likert questionnaire and spontaneous comments, has indicated that the software has facilitated the learning of physiological concepts and was a very stimulating activity. 